\title{
CHALLENGES OF IOT TECHNOLOGIES FOR BUSINESSES AND CONSUMERS
}

Please cite this article as:

Albăstroiu, I., 2021. Challenges of IoT Technologies for Businesses and Consumers. Amfiteatru Economic, 23(57), pp.321-323.

DOI: $10.24818 / \mathrm{EA} / 2021 / 57 / 321$

IoT (Internet of Things) is a concept and a paradigm that involves the ubiquity of large and diverse number of smart devices and active objects that can interact and cooperate with other devices and objects through wired and wireless connections and unique addressing schemes to create services and applications adapted to users' needs. The ability of smart devices to connect, communicate and transfer data has enabled the innovation and development of various solutions for industry, business organizations, and final consumers.

Currently, popular IoT solutions in the consumer segment (Consumer IoT) are those in the "smart home" category (which refers to applications for control and automation of lighting systems, ventilation, air conditioning, robotic vacuum cleaners, air purifier, air conditioners, ovens or refrigerators) and wearable devices ("wearables"), such as fitness bracelets or trackers and smart watches, allowing users to monitor and control their health.

Companies have embraced this tendecy very quickly, because the benefits are important: higher connectivity, easy access to data, interconnected ecosystems. All this translates into lower costs and efficiency in resource optimization. Commercial IoT projects are varied from collecting and analyzing information from customers through interconnected objects, to implementation of intelligent solutions for the office area (resources - such as water, gas, electricity or heat - become controllable by automation and monitoring in office buildings, industrial halls, warehouses, hotels, and can be distributed more efficiently, according to real needs).

Also, the applicability of IoT technology proves to be useful in optimizing production flows, intelligent power grids, connected industrial equipment and digital supply chain management. Industrial IoT (IIoT) refers to application of IoT technology in industrial settings, especially in terms of control the devices involving cloud technologies and allowing organizations to collect and analyze data from a variety of sensors (on production equipment, delivery trucks, pipelines, weather stations, smart meters etc.)

IoT applications have proven their technical feasibility, but there are still questions about their economic viability, especially from a business perspective. In this regard, concerns are raised about the high costs and length of time required to implement these solutions, the scarcity of suitably qualified staff and uncertainties about actual cost-effectiveness of such projects. In addition, there are concerns about the impact on environment and human health, data security and confidentiality, and many other unresolved ethical and legal issues.

In this context, this issue of Amfiteatru Economic journal is dedicated to identify the main benefits and challenges in all areas of IoT applicability, associated with use at the level of individual consumer, business organization or industry. Moreover, the issue dedicated to

Vol. $23 \cdot$ No. $57 \cdot$ May 2021 
this topic has offered the opportunity for academics and business professionals to present the results of their research, indicating the degree of understanding of the concept and its implications, as well as the current state and development trends in different sectors.

The concept of smart home has been drawing attention recently due to IoT. A home with IoT solutions is the one wherein electrical, electronic, and household appliances are connected to a central monitoring and control system, so that can be automatically turned on and off at certain times or if certain events occur. These smart home IoT solutions are the subject of the article "Adopting IoT-based Solutions for Smart Homes. The perspective of the Romanian Users", that presents areas of application, characteristics of the solutions dedicated to smart homes and the results of an exploratory research, that allowed identification of the level of understanding, degree of the adoption and, also, the associated benefits and challenges of these solutions, from the perspective of the Romanian users.

Nowadays, IoT technologies are successfully used in the field of education. The article "The IoT Technologies Acceptance in Education by the Students from the Economic Studies in Romania" investigates the factors that affect the IoT technologies adoption using a conceptual framework inspired by the Technology Acceptance Model - TAM, which explains the use of new technologies by adopting a causal relationship between beliefs, perceptions, attitudes, intentions and behavior. The results of the study show the existence of a positive correlation between the research variables and indicate that Romanian students from the economic studies are ready to accept the new technological advances in IoT and to implement them in their future jobs.

The adoption of IoT technologies in tourism is the issue addressed in the article "Factors that Influence the Adoption of the Internet of Things in Tourism by Romanian Consumers". The study is highlighting the specific determinants of IoT adoption in tourism, in general, and in reservation systems, especially, by presenting the causal relationship between the level of IoT adoption in tourism services and trust in these systems, on the one hand, and individual internal consumer behaviours, on the other hand. Influencing factors are grouped into six categories: awareness, confidentiality and safety, cost, convenience, social influence, and habits. The main results of the research conducted among Romanian tourists show the significant influence of behavioural variables related to awareness, convenience, habits, and cost. Among the socio-demographic factors, the role of age and education was highlighted, the younger and more educated people having higher probabilities of frequent use of the tourist services proposed by IoT systems.

A new theoretical model based on Technology Acceptance Model (TAM) was also developed and tested in the article "Wearable Technology Adoption among Romanian Students: a Structural Model Based on TAM" in order to identify the relations between factors influencing the attitude towards use and the intention to use of wearable devices. A survey carried out on Romanian students provided the necessary data to test the model. The results of Structural Equation Modelling (SEM), based on the Partial Least Squares (PLS) method, indicate that the three exogenous variables of the model (perceived usefulness, perceived enjoyment, and visual attractiveness of wearable devices) have a significant positive influence on endogenous variables (intention to use and attitude towards the use of wearable devices).

Successful innovation of the business model for IoT solutions requires companies to adopt strategic orientations towards market, technology, and entrepreneurship, creating the conditions for increasing long-term performance. Despite this, in the field of strategic 
management and marketing, limited efforts have been dedicated to studying the strategic factors of business model innovation for IoT solutions. To fill this knowledge gap, the paper "Business Model Innovation for IoT Solutions: an Exploratory Study of Strategic Factors and Expected Outcomes" contributes by deepening the understanding of the business model innovation phenomenon and guiding managers in this process. Through a qualitative research, consisting in semi-structured interviews with top managers at IT companies operating in Romania, that have successfully developed IoT solutions, the authors of this article have identified proactive market orientation, technology orientation, entrepreneurial orientation, and adaptive marketing capabilities as strategic factors of business model innovation for IoT solutions.

The article "Usage of Neural-Based Predictive Modeling and IIoT in Wind Energy Applications" aims to provide an overview on the use of predictive analytics based on neural networks and IIoT in the wind energy industry. The focus is on analytics, by identifying the theoretical and practical aspects of using network-based algorithms for rapid, short-term univariate predictions of wind energy production, using Romanian-based wind turbines data for the case study. The article demonstrates that Industrial Internet of Things is enabling the effective transition to wind energy through automation by removing many of the disadvantages in a way that has recently become accessible, creating a synergy of physical devices through advanced sensing capabilities, software, storage and analytics capabilities.

The use of IoT by individuals in their homes involves the reinterpretation of existing requirements regarding data protection, especially in terms of the ethics of using data and the security of personal data. The paper "Intrusiveness and Data Protection in IoT Solutions for Smart Homes" analyses the intrusiveness generated by aggregations of personal data, the responsibility for data protection and user's perception of these issues. It also presents the results of a quantitative research, showing that accessing certain types of data is perceived as being more intrusive than others, and that respondents rely on other users' reviews to learn how data protection is provided through the IoT device.

The paper "Internet of Things, Challenges and Perspectives in Romania: A Qualitative Research" makes a contextual analysis of the development and the future of Industrial IoT in Romania. Data collected from Romanian companies, by semi-structured interview, are presented in the paper and allow to identify the level of integration of IoT in the activity of companies, a first capture of potential risks perceived by users in industry, car transportation and support services, and the barriers in the implementation and use of IoT.

The devices used in everyday life are becoming more and more intelligent and interconnected. Thus, IoT is an emerging field. These technologies, that could allow literally billions of everyday objects to communicate with each other, have enormous potential to change our lives, to boost productivity, keep us healthier (or at least more careful and concerned with this aspect), make transportation more efficient, reduce energy consumption or make our homes more comfortable.

Associate Editor, Irina Albăstroiu 